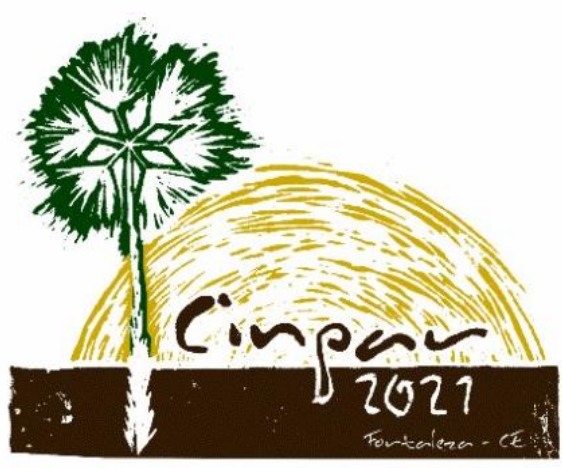

XVII Congresso Internacional sobre Patologia e Reabilitação das Construções

XVII Congreso Internacional sobre Patología y Rehabilitación de las Construcciones

XVII International Conference on Pathology and Constructions Rehabilitation

FORTALEZA (Brasil), 3 a 5 de junho de 2021

https://doi.org/10.4322/CINPAR.2021.126

\title{
Intervenção e preservação de patrimônio edificado: um caso de estudo no Porto, Portugal
}

\section{Intervention and safeguard of built heritage; a case study in Porto, Portugal}

\author{
lasmin dos SANTOS ${ }^{1}$, Rafael dos SANTOS ${ }^{2}$, João Miranda GUEDES ${ }^{3}$ \\ ${ }^{1}$ Faculdade de Engenharia da Universidade do Porto, Porto, Portugal, rssantos.iasmin@gmail.com \\ ${ }^{2}$ Faculdade de Engenharia da Universidade do Porto, Porto, Portugal, rafael_baldissera@hotmail.com \\ ${ }^{3}$ Faculdade de Engenharia da Universidade do Porto, Porto, Portugal, jguedes@fe.up.pt
}

\begin{abstract}
Resumo: O presente artigo expõe as parcialidades das intervenções de reabilitação estrutural em edificações, centrando-se no caso de estudo de uma habitação antiga típica do Porto, Portugal, constituída por paredes exteriores de alvenaria de pedra e paredes interiores, pavimento e cobertura de madeira. Este tipo de intervenção exige a análise prévia do estado real da edificação, a fim de identificar os elementos que necessitam de dações de reabilitação, reforço ou substituição. Assim o trabalho teve por base os dados recolhidos em ações prévias de inspeção do edifício que permitiram realizar o diagnostico do estado de conservação e das condições de segurança e de serviço dos elementos estruturais. Em seguida, empregando a metodologia BIM (Building Information Modeling), foram estudadas soluções para colmatar as debilidades encontradas, em particular na estrutura de madeira dos pavimento e cobertura. Foram adotadas soluções em estrutura metálicas e de madeira. No caso dos pavimentos, o uso de perfis metálicos se secção $\mathrm{H}$ mostrou ser uma boa opção, impactando de forma reduzida com a arquitetura, nomeadamente preservando os pésdireitos da edificação e permitindo atender todos os requisitos dos Estados Limites Últimos (segurança) e de Serviço (conforto - vibração e deformação). Tratando-se de uma construção edificada num país de Comunidade Europeia, o processo de verificação e dimensionamento obedeceu às normas vigentes neste espaço comunitário: Eurocódigos. Por fim, o artigo ressalta quês, apesar de existem inúmeras técnicas e soluções na área de reabilitação de edificações, a sua seleção tem de se apoiar numa boa caracterização prévia dos seus elementos construtivos originais: arquitetónicas, materiais, estruturais... de modo que a intervenção se possa adequar da melhor forma a essas características, garantindo a sua valorização como património histórico local.
\end{abstract}

Palavras-chave: Reabilitação estrutural, edificado antigo, BIM, eurocódigos

\section{Introdução}

Prática comum em vários países do mundo, a reabilitação de edifícios tem como objetivo a intervenção em imóveis com vista à sua preservação como elemento com valor histórico, arquitetónico, material, estrutural, garantindo, simultaneamente, as condições de segurança e conforto exigidas nos dias de hoje. Em Portugal, essa prática tem vindo a assumir uma relevância crescente, com uma maior aposta neste mercado por parte de projetistas e construtores e que acompanha uma maior consciencialização sobre o valor do edificado como elemento cultural identitário dos lugares.

As intervenções de reabilitação de edifícios antigos compreendem um grande número de especificidades e um nível de complexidade superior ao das construções correntes, exigindo conscientização e formação dos diversos agentes envolvidos. É indispensável um maior rigor na definição ao nível metodológico, estratégico, operacional e tecnológico. 
Neste contexto, o presente artigo expõe o caso de estudo de uma intervenção de reabilitação numa edificação situada na cidade do Porto. Descreve, de forma sucinta, as principais características materiais e estruturais do edifício, o seu estado de conservação e danos que afetam os seus diferentes elementos construtivos. Esta análise prévia é fundamental e é o elemento principal de suporte da proposta de soluções estruturais a desenhar e dimensionar no âmbito do projeto de arquitetura do edifício e dos quesitos regulamentares estipulados em Portugal, e que serão discutidas e apresentados no artigo.

\section{Caracterização do edifício em estudo}

Antes de qualquer tomada de decisão em relação à intervenção arquitetónica e estrutural, deverá ser feito o levantamento das características arquitetónicas, materiais estruturais e do estado de conservação do edifício de forma a poder fazer-se um diagnóstico prévio da situação existente. Esta informação, recolhida no local através de visitas técnicas e de documentação existente em arquivos, ou noutras fontes de informação, e tratada dá lugar à construção de um Relatório de Inspeção e Diagnóstico Estrutural (RIDE), que proporciona o conhecimento necessário à definição das estratégias de intervenção a propor, ou implementar. No presente caso, o RIDE foi realizado pelo gabinete de projeto NCREP, Consultoria em Reabilitação do Edificado e Património, Lda. (www.ncrep.pt), e que disponibilizou esta informação.

\subsection{Levantamento das caraterísticas construtivas}

A ação de inspeção ao edifício, realizada em fase prévia ao projeto de intervenção, permitiu constatar que se tratava de um imóvel de construção tradicional de alvenaria de pedra e madeira, possuindo uma área de aproximadamente $300 \mathrm{~m}^{2}$, distribuída por quatro pisos: rés-do-chão, 10, 2ㅇ e 3ㅇ pisos, este último recuado em relação à fachada principal, e duas coberturas: uma sobre parte do 20 piso e outra sobre o 30 piso (ver Figura 1).

Por se tratar de um edifício típico do Porto, Norte de Portugal, é constituído por paredes em alvenaria granítica, de folhas simples ou dupla, com espessuras médias variando, respectivamente, entre os $30 \mathrm{~cm}$ e $60 \mathrm{~cm}$. As paredes internas da edificação são de tabique simples, formadas por tábuas costaneiras, com espessura total média de $10 \mathrm{~cm}$, que têm como função fulcral compartimentar os espaços e auxiliar no suporte da estrutura das escadas.

Os pavimentos são materializados por vigas de madeira dispostas paralelamente entre si e às fachadas principal e de tardoz, apoiadas nas paredes de alvenaria de pedra das empenas. $\mathrm{O}$ assoalho, composto por tábuas de madeira, é pregado transversalmente à direção das vigas.
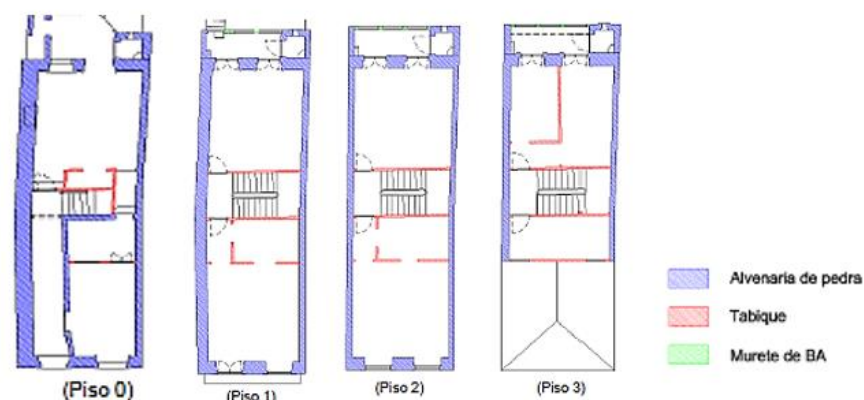

Figura 1 - Tipologia das paredes existentes no edifício

\subsection{Diagnóstico do estado de segurança e conservação}

De acordo com o RIDE, o imóvel em estudo apresentava um razoável estado de conservação estrutural e a maioria dos elementos estruturais poderiam ser mantidos através de intervenções pontuais de reabilitação e(ou) reforço. Indica ainda que os vigamentos em madeira estavam sujeitos a deformações acentuadas, empenos e pequenas degradações, mas que a maioria destes elementos estruturais poderiam ser mantidos, embora com substituições pontuais do vigamento. 
Em relação aos elementos estruturais de alvenaria de pedra, o RIDE conclui que não apresentavam danos relevantes, não considerando necessário proceder, com exceção de algumas zonas pontuais, à reabilitação e(ou) reforço estrutural da generalidade das paredes de alvenaria de pedra do edifício. Indica ainda que a cobertura apresentava um razoável estado de conservação, ainda que com falhas no sistema estrutural que tornariam necessário, na fase de projeto, conceber uma nova solução estrutural para as asnas.

Neste artigo, procedeu-se à análise exclusiva dos pavimentos em madeira e das paredes de alvenaria de pedra. A cobertura não foi abordada neste trabalho.

\section{Proposta arquitetónica}

A intervenção de reabilitação proposta pela arquitetura compreende a remodelação dos pisos elevados (10 ao 3 ㅇ piso), visando a alteração do edifício inicialmente com carácter unifamiliar para multifamiliar. No 20 e 3 o piso (recuado), a intervenção foi mais profunda, envolvendo a criação de mezaninos. A cobertura proposta apresenta alguns ajustes de forma a permitir integrar o espaço do desvão do telhado como área/volume útil da habitação nestes dois últimos pisos. Nos restantes pisos, o projeto de arquitetura propõe o reposicionamento de paredes interiores, dotando-se os espaços de compartimentação adequada ao uso requerido. A estrutura das escadas é mantida pela arquitetura (Figura 2).

Com a nova arquitetura, criaram-se as seguintes tipologias para a habitação:

- 3 T1 (no piso 0 e piso 2);

- 2 T0 (no piso 1 ).
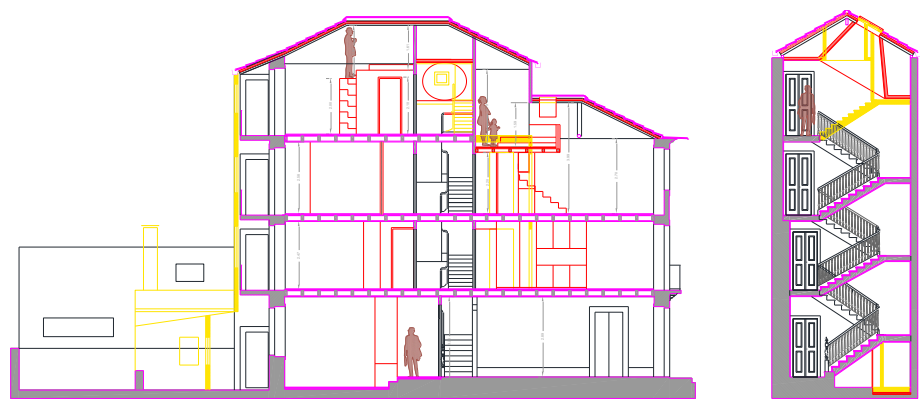

Figura 2 - Cortes longitudinais e transversal do edifício, retirados dos elementos da arquitetura: elementos a construir (em vermelho) e a demolir (em amarelo)

\section{Conceção e projeto de reabilitação}

\subsection{Ações consideradas}

As ações atuantes nos elementos estruturais dos pavimentos (vigas e assoalho) foram consideradas de acordo com o Eurocódigo 0, sendo:

- Peso próprio dos elementos de madeira;

- Paredes de gesso cartonado: carga de 0,50 KN/ $\mathrm{m}^{2}$ uniformemente distribuída sobre o assoalho;

- Forro de gesso: carga de 0,12 KN/m² uniformemente distribuída sobre o assoalho;

- Sobrecarga de $2,0 \mathrm{KN} / \mathrm{m}^{2}$, para o caso de edificações residenciais, uniformemente distribuída sobre o assoalho.

As vigas de madeira, que servem de suporte às tábuas do assoalho, foram consideradas como sendo elementos lineares simplesmente apoiados. Na realidade, a conexão às alvenarias, mesmo no caso em que não existem ferrolhos na ligação às paredes, materializa um apoio que se encontra entre uma ligação perfeitamente encastrada (sem rotações) e um apoio de rotação livre. Assim, considerando-se uma abordagem conservadora, optou-se pelo último cenário, pois este resulta em deslocamentos e momentos atuantes maiores. Note-se que no caso das vigas de madeira, a resistência aos momentos negativos é igual à dos momentos positivos. 


\subsection{Verificação de segurança}

A verificação de segurança, foi realizada majoritariamente nos elementos estruturais de madeira, uma vez que são os que apresentam o maior número de condicionantes. Conforme mencionado previamente, os pavimentos são constituídos por vigamento de madeira, mais especificamente castanho (Castânea sativa Mil.) de seção retangular. A madeira encontrada enquadrava-se na classe de resistência D30, de acordo com classificações da norma UNI EN 338 - Structural Timber.

A verificação face à ELU passa por garantir a segurança das vigas ao esmagamento na zona dos apoios, aos esforços de corte nas extremidades e aos momentos fletores a meio vão. No caso dos ELS, será necessário garantir que as peças não apresentem flechas instantânea e a tempo infinito e períodos naturais de vibração superiores aos limites regulamentares.

\subsubsection{Estado Limite Últimos: ELU}

A análise perante esforços de corte e flexão, além do esmagamento da seção transversal na região dos apoios, segue os critérios presentes no Eurocódigo 5.

\subsubsection{Esforço de corte}

A tensão tangencial máxima $\tau_{\text {max }}$ para um elemento linear de secção transversal retangular é determinado pela expressão:

$$
\tau_{\max }=1,5 \frac{\mathrm{V}}{\mathrm{bh}}
$$

Sendo $V$ o esforço cortante máximo atuante, $b$ e $h$ correspondem, respectivamente, à largura e à altura da seção transversal considerada. O critério de verificação de segurança ao corte de elementos de madeira consiste em limitar o valor de cálculo da tensão tangencial atuante ao valor de cálculo da resistência ao corte da madeira, $f_{v, d}$, ou seja:

$$
\tau_{\text {max }} \leq f_{v, d}=K_{\text {mod }} \cdot \frac{f_{v, k}}{\gamma_{m}}
$$

Em que $f_{v, k}$ é a tensão resistente característica da madeira, $\gamma_{m}$ representa o coeficiente de minoração, igual a 1,3, para o caso de madeira maciça, e $K_{m o d}$ é um fator de modificação da resistência, que tem em conta o efeito da duração das ações e o teor de água da madeira. Para este caso, a norma recomenda que $K_{\bmod }$ assuma o valor de 0,6 .

\subsubsection{Momento fletor}

Deve-se verificar a resistência dos elementos lineares ao momento fletor, considerando-se o efeito da flambagem lateral com torção. Para o caso de secções retangulares de madeira maciça, o Eurocódigo 5 determina que a tensão atuante na madeira seja limitada a:

$$
\sigma_{m, \text { crit }}=\frac{0,78 b^{2}}{h \cdot l_{e f}} E_{0,05}
$$

$E_{0,05}$ diz respeito ao percentil de $5 \%$ do módulo de elasticidade paralelo à fibra da madeira. 0 comprimento efetivo é representado pela variável $l_{e f}$ que, para o caso de vigas simplesmente apoiadas com carregamento uniformemente distribuído, é definido como sendo $90 \%$ do comprimento real do elemento analisado.

O critério de segurança genérico consiste em limitar o valor máximo (em módulo) de cálculo da tensão atuante de flexão ao valor de cálculo da resistência à flexão.

$$
\sigma_{m, d} \leq k_{\text {crit }} \cdot K_{\text {mod }} \cdot \frac{f_{m, k}}{\gamma_{m}}
$$

$\sigma_{m, d}$ é a tensão atuante de cálculo, igual a $6 M_{d} /\left(b \cdot h^{2}\right)$ para o caso de seções retangulares, $k_{c r i t}$ é um coeficiente que expressa a redução da resistência ao momento fletor devido a flambagem lateral com torção e é função o índice de esbeltez $\left(\lambda_{r e l, m}\right)$ do elemento analisado.

\subsubsection{Esmagamento nos apoios}


A verificação da compressão perpendicular ao fio é definida pela imposição de um limite superior de cálculo da tensão atuante de compressão:

$$
\sigma_{c, 90, d} \leq k_{c, 90} \cdot f_{c, 90, d}
$$

$\sigma_{c, 90, d}$ é o valor de cálculo da tensão atuante de compressão perpendicular ao fio, $f_{c, 90, d}$ é o valor de cálculo da tensão resistente de compressão perpendicular ao fio e $k_{c, 90}$ é um coeficiente que traduz o efeito da variação da resistência da peça com a geometria e com a extensão da zona carregada.

Por via de regra, o fator $k_{c, 90}$ deve ser tomado como unitário, embora em vigas sobre apoios discretos com $h \leq I_{1} / 2$ (Figura 7), os valores de $k_{c, 90}$ a adotar são de 1,50 . $O$ uso de valores elevados de $k_{c, 90}$ pode dar origem a deformações transversais de compressão de até $10 \%$. Tais deformações podem vir a causar problemas relacionados sobretudo com a utilização, mas também com as ligações que forem afetadas.

\subsubsection{Estado Limite de Serviço: ELS}

Os valores informados nos subcapítulos seguintes para verificação em ELS (deformações e vibrações) foram retirados do Eurocódigo 5.

\subsubsection{Deformações}

Para o caso das deformações instantâneas, calcula-se considerando-se uma combinação característica de ações e utilizando-se parâmetros de resistência médios dos módulos de elasticidade e de distorção do material. A flecha a tempo infinito é determinada para a combinação quase permanente de ações e utiliza parâmetros de resistência médios corrigidos por um coeficiente $k_{\text {def }}$, que tem em conta os efeitos da fluência. Tal coeficiente depende do tipo de madeira utilizada (sólida ou lamelada colada) e da Classe de Serviço (ambiente interior, protegido ou não protegido, ou ambiente exterior).

Os limites estabelecidos pelo Eurocódigo 5 para as flechas instantâneas $w_{\text {inst }}$ e a tempo infinito $w_{\text {fin }}$ no caso de vigas simplesmente apoiadas de comprimento $l$, são:

$$
w_{\text {inst }} \leq l / 300 \text { a } l / 500 \text { e } w_{\text {inf }} \leq l / 150 \text { a } l / 300
$$

\subsubsection{Vibrações}

O Eurocódigo 5 aconselha que, para que o caso de pavimentos em madeira de edifícios residenciais, a frequência do primeiro modo natural de vibração vertical seja superior a $8 \mathrm{~Hz}$, a fim de evitar qualquer desconforto aos utilizadores. Além disso, estabelece um procedimento simplificado para o cálculo da frequência do primeiro modo de vibração a partir da relação seguinte:

$$
f_{1}=\frac{\pi}{2 l^{2}} \sqrt{\frac{(E I)_{l}}{m}}
$$

Sendo $l$ a maior dimensão do pavimento, $m$ a massa uniformemente distribuída sobre $o$ assoalho (considerando apenas o peso próprio do mesmo e das vigas de madeira que o apoiam) e $(E I)_{l}$ representa uma rigidez equivalente do pavimento na direção perpendicular às vigas de madeira.

\subsubsection{Resumo das verificações}

\subsubsection{Pavimentos}

Foi escolhido um pavimento do piso 1 junto à fachada principal, de geometria mais ou menos retangular, com dimensões de $4,68 \times 6,34 \mathrm{~m}^{2}$, que se considerou como sendo representativo deste estudo. $O$ pavimento apresenta nove vigas retangulares com seções distintas (base variando entre 11 e $18 \mathrm{~cm}$ e altura variando entre 12 e $22 \mathrm{~cm}$ ). Note-se que o assoalho, quando bem fixo às vigas (num pavimento construído de acordo com as boas regras da arte, todas as tábuas do assoalho pregam em todos as vigas que encontram), exerce a função de conectar as vigas entre si, a fim de permitir com que toda a estrutura do pavimento trabalhe de forma conjunta. Em particular, ao aplicarem-se cargas sobre o pavimento, estas são direcionadas 
preferencialmente para as vigas que apresentam maior rigidez/secção/resistência, reduzindo os esforços nas vigas de menor resistência, ou seja, uniformiza o comportamento do pavimento, em particular a sua deformação. Tal comportamento permite adotar uma simplificação na modelação estrutural a partir da adoção de uma seção única com propriedades geométricas (área e inércia) médias.

Tendo como base as seções utilizadas, adotou-se uma seção transversal de área e inércia médias igual a média simples das áreas e inércias das vigas que sustentam o assoalho, obtendo-se $A_{\text {média }}$ de $228 \mathrm{~cm}^{2} \mathrm{e}$ $I_{\text {média }}$ de $5427 \mathrm{~cm}^{2}$, o que corresponde a uma seção de largura $b$ igual a $13,5 \mathrm{~cm}$ e altura $h$ de $16,9 \mathrm{~cm}$.

As vigas foram modeladas com elementos lineares. Para o assoalho de madeira, utilizaram-se elementos finitos de casca com quatro nós, definindo-se para este caso um material ortotrópico, com a rigidez principal perpendicular à direção das vigas de madeira e igual à do assoalho, e $10 \%$ do valor da rigidez principal na direção paralela às vigas. Esta condição visa simular com maior precisão o comportamento das tábuas que compõem o assoalho e que se dispõem transversalmente às vigas de apoio do pavimento.

Constata-se, de um modo geral, que em edifícios com esta tipologia, o fator que mais condiciona a verificação dos pavimentos é o ELS de vibração do pavimento. No caso do pavimento em análise, a frequência do primeiro modo de vibração determinada pelo modelo em elementos finitos é de $6,46 \mathrm{~Hz}$, valor que é idêntico ao calculado através da metodologia simplificada do Eurocódigo 5 (Equação 9), 6,50 Hz, sendo ambos inferiores ao limite de $8 \mathrm{~Hz}$ definido por esta Norma Europeia.

Para além disso, o pavimento somente verifica a segurança ao esforço de corte e ao esmagamento nos apoios, ocorrendo violações nas verificações de segurança com relação ao momento fletor (considerando-se o efeito da flambagem lateral com torção) e às deformações instantâneas e a tempo infinito.

Quadro 1 - Verificações das vigas de madeira do pavimento não reforçado
\begin{tabular}{|l|c|}
\hline$\tau_{\text {max }}=547 \mathrm{kPa}<1385 \mathrm{kPa}=f_{v, d}$ & $\checkmark$ \\
\hline$\sigma_{m, d}=16,42 \mathrm{MPa}>13,85 \mathrm{MPa}=k_{c r i t} \cdot f_{m, d}$ & $\times$ \\
\hline$\sigma_{c, 90, d}=0,62 \mathrm{MPa}<3,69 \mathrm{MPa}=k_{c, 90} \cdot f_{c, 90, d}$ & $\checkmark$ \\
\hline$w_{\text {inst }}=27,0 \mathrm{~mm}>15,6 \mathrm{~mm}=l / 300$ & $\times$ \\
\hline$w_{f i n}=35,2 \mathrm{~mm}>31,2 \mathrm{~mm}=l / 150$ & $\times$ \\
\hline$f_{1}=6,46 \mathrm{~Hz}<8,0 \mathrm{~Hz}$ & $\times$ \\
\hline
\end{tabular}

\subsubsection{Paredes de alvenaria}

A verificação das paredes de alvenaria de granito passou por cumprir dois requisitos:

- Tensões de compressão de cálculo máximas instaladas em ELU de 1,5 MPa (tensão resistente de cálculo). A resistência característica à compressão de paredes de alvenaria granítica pode ser considerada, de acordo com a norma italiana NTC 2018, igual a 3,0 MPa. Considerando-se um material de maior heterogeneidade de suas propriedades físicas, assume-se um coeficiente de redução da resistência igual a 2,0 .

- Inexistência de zonas tracionadas (trações de baixa magnitude devido a cargas pontuais aplicadas pelas vigas do assoalho ou causadas por aberturas são permitidas).

Deve-se dar uma atenção especial às cargas horizontais, como são as ações devidas ao vento e ao sismo, pois tendem a fletir as paredes de alvenaria e com isso tracioná-las. O peso próprio das paredes influencia de maneira positiva à estabilidade das paredes, enquanto a existência de grandes aberturas provoca descompressões e promove a ocorrência de zonas tracionadas.

Após a modelagem em elementos finitos da edificação, constatou-se que a tensão máxima de compressão é de 1,32 MPa, valor abaixo da tensão resistente de cálculo. Observaram-se somente tensões de tração reduzidas localizadas junto das aberturas dos vãos das fachadas.

Por atender as verificações regulamentares, não houve necessidade de intervenção ao nível das alvenarias. 

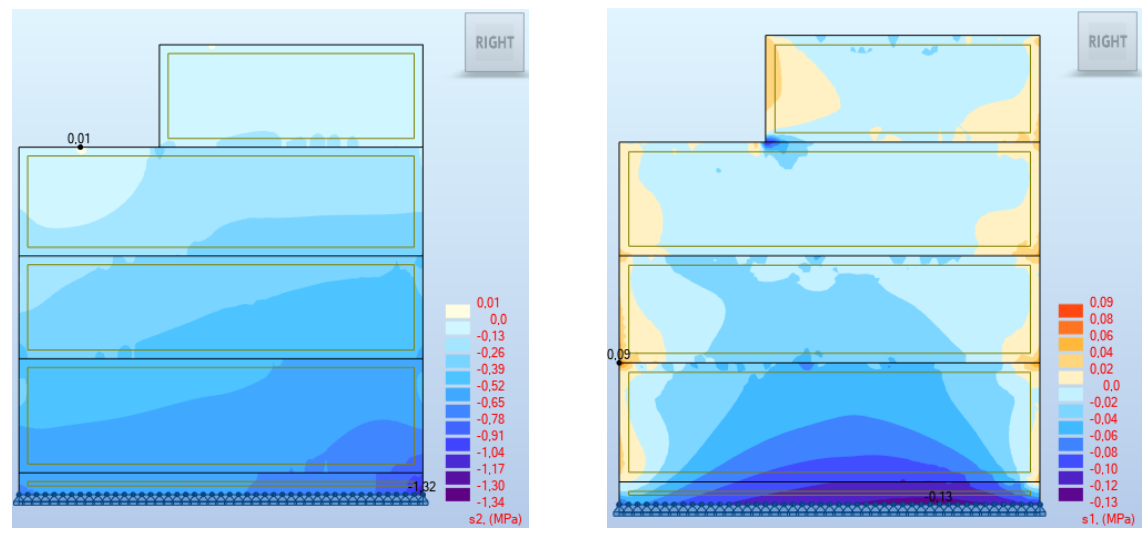

Figura 2 - À esquerda, mapa de tensões de compressão; à direita, mapa de tensões de tração

\section{Soluções de intervenção}

Após a verificação de segurança de todos os elementos existentes, os que verificaram os requisitos regulamentares foram mantidos sem necessidade de implementar qualquer solução de intervenção. Em contrapartida, para os elementos que não cumpriram as verificações de segurança, foram propostas medidas de intervenção.

\subsection{Pavimentos}

No caso dos pavimentos que não cumpriram os requisitos regulamentares, como foi o caso do pavimento detalhado anteriormente, a solução adotada passou pelo reforço dos pavimentos com a instalação de novas vigas metálicas entre as vigas existentes.

É aconselhável o emprego de perfis que possuam rigidez flexional próxima das dos elementos existentes, de maneira a permitir uma deformação conjunta do pavimento mais harmoniosa e garantir um melhor equilíbrio na distribuição de esforços pelas várias vigas. O perfil escolhido, HE100A de aço do tipo S275, veio a atender os requisitos de segurança e os aspetos agora referidos, garantindo ainda a altura do pé direito existente.

Observa-se que, após reforço, os esforços de corte $V_{E d \text {,max }}$ e flexão $M_{E d \text {,max }}$ máximos e as deformações instantâneas $w_{\text {inst,max }}$ e a tempo infinito $w_{\text {fin,max }}$ reduziram-se consideravelmente. Além disso, a frequência do primeiro modo de vibração $f_{1}$ do pavimento encontra-se acima do valor limite indicado pelo Eurocódigo 5.

$$
\begin{array}{ll}
- & V_{E d, \text { max }}=4,24 \mathrm{KN} \\
- & M_{E d, \text { max }}=5,27 \mathrm{KN} . \mathrm{m} \\
- & w_{\text {inst,max }}=13,6 \mathrm{~mm}
\end{array}
$$

$$
\begin{aligned}
& -\quad w_{\text {fin, } \max }=17,9 \mathrm{~mm} \\
& -\quad f_{1}=8,69 \mathrm{~Hz}
\end{aligned}
$$

Em ELU, garantiu-se um fator de segurança $F S$ (rácio entre esforços resistente e atuante) igual a 5,0 para tensões tangenciais e igual a 1,7 para tensões de flexão.

O perfil HE100A apresenta resistência ao corte de $120,03 \mathrm{KN}$ para tensões tangenciais paralelas à alma e resistência ao momento fletor, considerando-se o efeito de flambagem lateral com torção para uma viga simplesmente apoiada de 4,68 m de comprimento, de 9,06 kN.m. Estes valores foram calculados levando-se em consideração os preceitos presentes no Eurocódigo 3. Os esforços atuantes máximos nas vigas metálicas do pavimento analisado, em ELU, foram de 5,16 KN para o esforço de corte e 6,50 KN.m para o momento fletor. Tais valores encontram-se abaixo dos valores limites indicados acima, verificando-se a segurança. A configuração final para o pavimento analisado encontra-se representado na Figuras 13 indicada abaixo: 


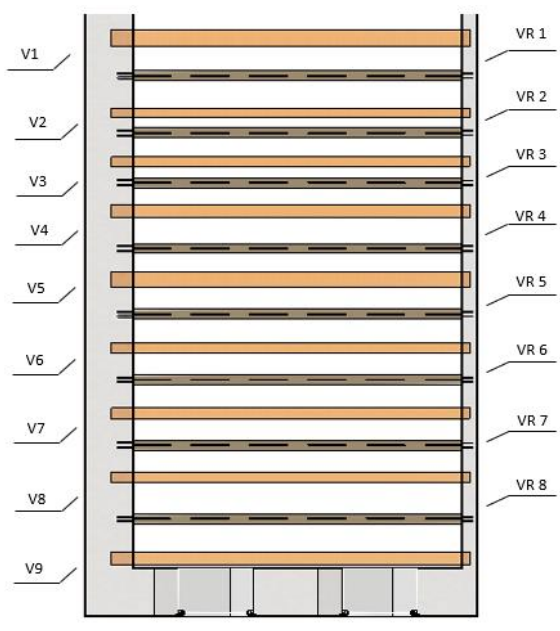

Figura 3 - Representação do pavimento reforçado

\section{Conclusões}

A reabilitação de edifícios é uma ação que se vê cada vez mais necessária, devido a crescente consciência da necessidade de proteger os bens imóveis com valor identitário cultural dos lugares. A decisão de realizar um projeto de reabilitação ou reforço em edifícios desta tipologia deve ter como propósito melhorar o seu comportamento, garantindo o respeito dos requisitos regulamentares e, simultaneamente, deve envolver técnicas pouco invasivas e que minimizem as alterações à estrutura original. Este duplo objetivo obriga a pensar em soluções caso a caso, preferindo as que melhor se adaptem às características arquitetónicas, estruturais e materiais de cada edifício, mas também ao seu estado de conservação e alterações arquitetónicas propostas.

O presente artigo procurou exemplificar a conceção de modelos numéricos de elementos finitos de forma a simplificar as estratégias de implementação, reformulação e adaptações necessárias a nível de projeto. Através destes modelos foram realizadas verificações de segurança, de acordo com as normas vigentes, e propôs-se uma solução de reforço para a melhoria do comportamento estrutural dos pavimentos. A adoção de perfis metálicos intercalados com as vigas de madeira dos pavimentos pode ser uma opção interessante, se for desenhada de forma a garantir a sua boa integração na arquitetura dos espaços e um bom comportamento estrutural, ou seja, uma redistribuição de esforços equilibrada entre vigas e uma deformação harmoniosa do pavimento.

Neste estudo não se analisaram as ligações entre os novos elementos metálicos e as paredes de alvenaria existentes. Estas ligações devem ser bem ponderadas de forma a garantir uma boa transmissão de esforços entre os elementos e a não introdução de esforços anómalos nos elementos existentes.

\section{Referências Bibliográficas}

Oliveira, R.A.F. (2003) Análise de práticas de conservação e reabilitação de edifícios com valor patrimonial. Tese de Mestrado. Facultade de Engenharia do Porto, Portugal

NP EN 1990:2009 Eurocódigo 0: Base para projetos de estrutura

NP EN 1991-1-1:2009 Eurocódigo 1: Acções em estruturas. Parte 1-1: Acções gerais. IPQ, 2009

NP EN 1991-1-4:2010 Eurocódigo 1: Acções em estruturas. Parte 1-4: Acções do vento. IPQ, 2010

NP EN 1993-1-1:2010 Eurocódigo 3: Projeto de estruturas de aço. Parte 1-1: Regras gerais e regras para edifícios. IPQ, 2010

NP EN 1995-1-1:2004 Eurocódigo 5: Design of timber structures. Parte 1-1: Common rules and rules for building. CEN, 2010

MIT (2018) NTC 2018: D.M. del Ministero delle Infrastrutture e dei Trasporti del 20/02/2018. Nuove Norme Tecniche per le Costruzioni. G.U. n. 42 del 17.01.2018, S.O. n. 8 